\title{
OPEM
}

www.opem.org

Oriental Pharmacy and Experimental Medicine 2009 9(4), 315-319

DOI 10.3742/OPEM.2009.9.4.315

\section{A pentacyclic triterpenoid possessing analgesic and anti-inflammatory activities from the fruits of Dregea volubilis}

\author{
M Biswas ${ }^{1, *}$, K Biswas $^{2}$, AK Ghosh ${ }^{3}$ and PK Haldar ${ }^{4}$ \\ ${ }^{1}$ Bengal Institute of Pharmaceutical Sciences, Kalyani, Nadia-741 235, India; ${ }^{2} B C D A$ College of Pharmacy \& \\ Technology, Barasat, Kolkata-700 127, India; ${ }^{3}$ Bengal School of Technology, Delhi Road, Hooghly-712 102, \\ India; ${ }^{4}$ Department of Pharmaceutical Technology, Jadavpur University, Kol-32, India
}

Received for publication January 19, 2009; accepted March 20, 2009

\begin{abstract}
SUMMARY
In present study evaluate the analgesic and anti-inflammatory activity of the compound obtained from the petroleum ether $\left(40-60^{\circ} \mathrm{C}\right)$ extract of the fruits from Dregea volubilis in Swiss albino mice and in Wister albino rats respectively. Dried and crushed fruits of Dregea volubilis were extracted by petroleum ether $\left(40-60^{\circ} \mathrm{C}\right)$, the proper solvent system was developed by TLC and subjected to column chromatography for obtaining the pure compound/s. IR, MASS, NMR (PMR, C13 NMR and DEPT) spectroscopic analysis were done to elucidate the structure of the compound/s. The petroleum ether $\left(40-60^{\circ} \mathrm{C}\right)$ extract of the fruits of Dregea volubilis led to isolation of a pentacyclic triterpenoid designated as taraxerone and characterized as D- friedoolean- 14- en, 3 one. Taraxerone had been screened for analgesic activity in Swiss albino mice and anti-inflammatory activity in Wister albino rats at the dose of $5 \mathrm{mg} / \mathrm{kg}$ body weight orally and exhibit significant analgesic and anti-inflammatory properties.
\end{abstract}

Key words: Dregea volubilis Benth; Pentacyclic triterpenoid; Taraxerone; Spectroscopy (IR, MASS, C13NMR, PMR, DEPT); Analgesic activity; Anti-inflammatory

\section{INTRODUCTION}

Dregea volubilis (Linn. f.) Benth ex. Hook f. Syn: Wattakaka volubilis (Linn. f.) Stapf; Marsedenia volubilis (Cooke) belongs to the family Asclepiadaceae and is commonly known as "Jukti" in Bengal. It is a tall woody climber of $11 \mathrm{~m}$. of height and $95 \mathrm{~cm}$. in girth with densely lenticulate branches, occurring throughout the hotter parts of India and Car Nicober Islands ascending to an altitude of $1500 \mathrm{~m}$. The leaves are employed in application for boils and abscesses (Sahu et al., 2002). Roots and tender

\footnotetext{
*Correspondence: M Biswas, Bengal Institute of Pharmaceutical Sciences, Kalyani, Nadia-741 235, India. Tel: +913325211273; E-mail: moulisha_biswas@yahoo.co.in
}

stalks are used as emetic and expectorant (Sahu et al., 2002). It is reported that an alcohol (50\%) extract of the plant showed activity on the central nervous system as well as anticancer activity against Sarcoma 180 in mice (Sahu et al., 2002). The maximum tolerated dose was found to be $500 \mathrm{mg} / \mathrm{kg}$ body weights of albino mice (Sahu et al., 2002). Two pregnane glycosides dregeosides isolated from this plant collected from Thailand showed antitumor activities against melanoma B-16 in mice (Panda et al., 2003). Reichstein and co- workers studied the components of the seeds of the plant and deduced the structure of drevogenins A, B, D and P. In later years, it is reported the isolation and characterization of twelve polyhydroxy C/D cis-pregnane glycosides 
from the same plant (Panda et al., 2003). Isolation of $\beta$ - sitosterol, kaempherol-3- galactoside, a 2- deoxy sugar, drevogenin A, drevogenin P, D -cymarose and L- olendrose from the plant has also been reported (Panda et al., 2003).

Present work is based on the chemical studies on naturally occurring bioactive triterpenes. It is reported herein the isolation and characterization of a pentacyclic triterpenoid designated as taraxerone having analgesic and anti-inflammatory activity, from the petroleum ether extract of the fruits of this medicinal plant. Previously taraxerone (Nobuo et al., 1987) was isolated from the plant Myrica Rubra and had shown its inhibitory activity on reverse transcriptase on human immunodeficiency virus (Goreti et al., 2005).

\section{MATERIALS AND METHODS}

\section{General procedure}

All melting points were measured on Yanagimoto micromelting apparatus and are uncorrected IR spectra were determined using JASCO 7300FTIR spectrometer. Optical rotations were measured using a JASCO DIP-370 digital polarimeter. ${ }^{1} \mathrm{H}$ and ${ }^{13} \mathrm{C}$ NMR spectra were recorded at 500 and $125 \mathrm{MHz}$ respectively by using a Jeol ECP-500 spectrometer in C5D5N with TMS as internal standard. HRFABMS was performed on a JEOL MS-700 mass spectrometer. TLC was carried out on silica gel 60F254 and spots were visualized by spraying with Libermann-Buchard's reagent followed by heating. Silica gel (silica gel 60, Merck) was used for column chromatography.

\section{Plant material}

The fruits of Dregea volubilis were collected from South 24-Parganas, West Bengal in the month of July 2007 and were authenticated from Indian Botanic Garden, Howrah, West Bengal, India. A voucher specimen (voucher no CNH/I-I/(267)/ 2008/Tech II/267) has been preserved in our research laboratory for future reference.

\section{Extraction and isolation}

The shade dried powdered fruits of Dregea volubilis $(2.4 \mathrm{~kg})$ were extracted thrice successively with $8 \mathrm{lt}$ Petroleum ether $(3 \times 8 \mathrm{lt})$, at ambient temperature. The combined Petroleum ether extract was concentrated and 18gms of extract was applied to a column of silica gel $60(400 \mathrm{~g})$ and washed with Petroleum ether. Gradient elution was carried out with mixture of chloroform-petroleum ether (1:9, 1:4, 3:7, 2:3 and 1:1). A total of 72 fractions (50 ml) were collected and the fractions which only gave the similar spots on TLC were combined. Fractions eluted with chloroform-petroleum ether (2:3) giving the mixtures of three spots were combined and subjected to re-chromatography over silica gel $(20 \mathrm{~g})$ for further purification. In case of further purification, fractions (collected $15 \mathrm{ml}$ lots) eluted with chloroformpetroleum ether mixture (1:1) furnished Taraxerone $(1.5 \mathrm{~g})$. Percentage wise $8.3 \%$ of the crude extract was the Taraxerone.

\section{Analgesic activity}

The pharmacological screening of the compound obtained from the petroleum ether extract of the fruits of Dregea volubilis was carried out using standard protocols (Mukherjee, 2007). The compound was suspended in $2 \%$ DMSO for administration to Swiss albino mice (Parkes et al., 1965).

\section{Acetic acid induced writhing reflex}

Swiss albino mice were divided into three groups $(\mathrm{n}=6)$. Group I received acetic acid $(1 \% \mathrm{v} / \mathrm{v}, 10$ $\mathrm{ml} / \mathrm{kg}$ b.w., i.p.) and writhing reflex was noted for the period of $15 \mathrm{~min}$. Group II and III received aspirin and taraxerone at the doses of $(300 \mathrm{mg} / \mathrm{kg}$, b.w., p.o.) and ( $5 \mathrm{mg} / \mathrm{kg}$, b.w., p.o.) respectively. 30 min after aspirin and taraxerone group II and III received acetic acid ( $1 \% \mathrm{v} / \mathrm{v}, 10 \mathrm{ml} / \mathrm{kg}$ b.w., i.p.) and writhing reflex was noted for the period of $15 \mathrm{~min}$.

\section{Anti-inflammatory activity}

The pharmacological screening of the compound obtained from petroleum ether extract of Dregea 
volubilis was carried out using standard protocols (Mukherjee, 2007). The crude extract was suspended in $2 \%$ DMSO for administration to albino rats.

\section{Carrageenan induced rat paw oedema}

The rats were divided into three groups containing six rats in each group. Acute inflammation was induced according to the method of Winter et al. (1957). $0.1 \mathrm{ml}$ of $1.0 \%$ carrageenan in normal saline $(0.9 \% \mathrm{w} / \mathrm{v} \mathrm{NaCl})$ was injected to the subplantar region (Bhatt et al., 1977) of right hind paw. The compound was administered to the rats $1 \mathrm{~h}$ before carrageenan injection. Different groups were treated as followes:

Group I: Carragenan (0.1 ml of 1.0\% carrageenan/ rat to the subplantar region).

Group II: Carragenan + Indomethacin $(10 \mathrm{mg} / \mathrm{kg}$ b.w., p.o.)

Group III: Carragenan + Taraxerone $(5 \mathrm{mg} / \mathrm{kg}$ b.w., p.o.)

The paw volume was measured initially and at 1 , 2, 3 and $4 \mathrm{~h}$ after carrageenan injection, using Plethysmograph, inflammation was calculated for comparison (Majumder et al., 2000).

\section{RESULTS}

In vitro analgesic and anti-inflammatory activities of the isolated compound from the petroleum ether $\left(40-60^{\circ} \mathrm{C}\right)$ extract of Dregea volubilis fruits have been shown in the Table 1 and 2 and Fig. 2 and 3 . The active fraction has been eluted with petroleum ether-chloroform mixture in the column chromatography made by silica gel led to isolation of the pentacyclic triterpenoid (Shashi et al., 1992).

Taraxerone (Fig. 1) was crystallized from methanol as colorless crystalline needles m.p. $239-242^{\circ} \mathrm{C}$, $[\alpha] \mathrm{D}+9.72\left(\mathrm{c}, 1.04, \mathrm{CHCl}_{3}\right)$. The compound gave positive Libermann-Burchard test indicating the presence of a pentacyclic triterpenoid ketone which was confirmed by total spectral studies by eluciding the structure of the compound. Compound (Fig. 1) exhibited in its IR Spectrum absorption bands at $1708,1473,1375,996$ and $818 \mathrm{~cm}^{-1}$ attributed to keto group and olefinic double bond. The ESI-TOF

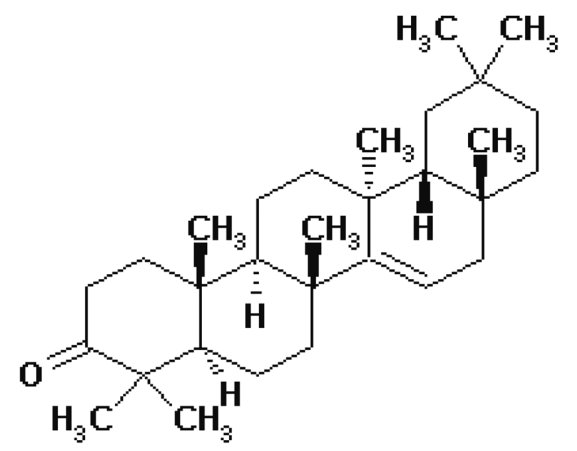

Fig. 1. Taraxerone.

Table 1. Analgesic effect of Taraxerone on acetic-acid induced writhing in mice $(n=6)$

\begin{tabular}{lccc}
\hline Treatment & Dose & Mean no of writhing \pm S.E.M. & \% Inhibition \\
\hline Acetic acid $(1 \% \mathrm{v} / \mathrm{v})$ & $10 \mathrm{ml} / \mathrm{kg}$ & $52.83 \pm 1.400$ & - \\
Acetic acid + Aspirin & $300 \mathrm{mg} / \mathrm{kg}$ & $17.66 \pm 1.606^{* *}$ & 66.57 \\
Acetic acid + Taraxerone & $5 \mathrm{mg} / \mathrm{kg}$ & $34.00 \pm 1.291^{* *}$ & 35.64 \\
\hline
\end{tabular}

Values are mean \pm S.E.M. One way ANOVA with Tukey-Kramer multiple comparison post test. ${ }^{* *} P<0.001$ when compared to control.

Table 2. Anti-inflammatory effect of Taraxerone on carrageenan induced rat paw edema $(n=6)$

\begin{tabular}{lccccc}
\hline Treatment & $1 \mathrm{~h}$ & $2 \mathrm{~h}$ & $3 \mathrm{~h}$ & $4 \mathrm{~h}$ & $\%$ Inhibition \\
\hline Carrageenan $(1 \% \mathrm{w} / \mathrm{v})$ & $0.73 \pm 0.08$ & $1.40 \pm 0.57$ & $1.80 \pm 0.57$ & $1.66 \pm 0.08$ & - \\
Carrageenan + Indomethacin $(10 \mathrm{mg} / \mathrm{kg})$ & $0.20 \pm 0.05^{*}$ & $0.50 \pm 0.05^{* *}$ & $0.36 \pm 0.03^{* *}$ & $0.23 \pm 0.03^{* *}$ & $88.9 \%$ \\
Carrageenan+ Taraxerone $(5 \mathrm{mg} / \mathrm{kg})$ & $0.30 \pm 0.05^{*}$ & $0.53 \pm 0.03^{* *}$ & $0.40 \pm 0.05^{* *}$ & $0.33 \pm 0.03^{* *}$ & $84.0 \%$ \\
\hline
\end{tabular}

Values are mean \pm S.E.M. One way ANOVA with Tukey-Kramer multiple comparison post test. ${ }^{* *} P<0.001$ when compared to control. ${ }^{*} P<0.01$ when compared to control. 


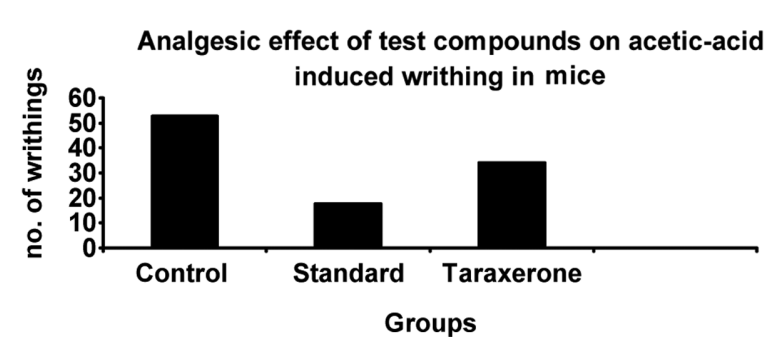

Fig. 2. Graphical representation of analgesic activity.

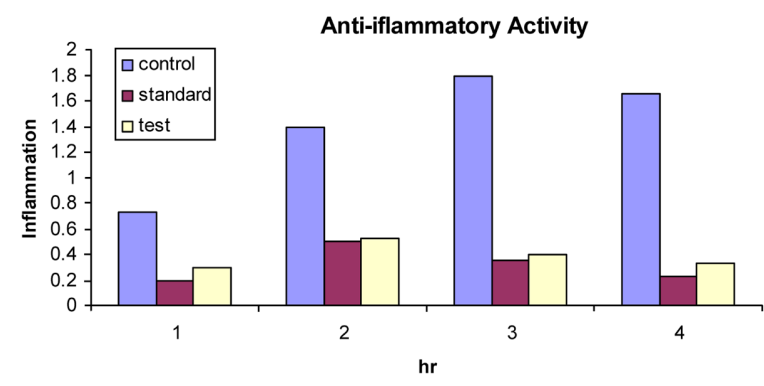

Fig. 3. Graphical representation of anti-inflammatory activity of Taraxerone.

mass spectrum displayed a sodiated molecular ion peak at $\mathrm{m} / \mathrm{z} 447.39$ indicating the molecular weight of the compound to be 424 and its molecular formula $\mathrm{C}_{30} \mathrm{H}_{48} \mathrm{O}$. The ${ }^{1} \mathrm{H}$ NMR spectrum of the isolated compound displayed eight methyl signal (all singlets) at $\delta 0.83,0.90,0.91,0.95,1.06,1.08,1.08$ and 1.14. The spectrum also showed one double doublet at $\delta 5.56(\mathrm{~J}=7.8$ and $2.7 \mathrm{~Hz})$ ascribed to an olefinic proton.

The ${ }^{13} \mathrm{C}$ NMR spectrum of the compound indicated the presence of thirty carbons in the compound. All the carbons resonances were assigned by multiplicity information obtained from Distortionless Enhancement by Polarization Transfer (DEPT). The spectrum revealed the presence of eight methyls, ten mythelenes, four methines and eight quaternary carbons. The singlet at $\delta 217.9$ unambiguously demonstrated the presence of a carbonyl group attached to a six member ring. The singlet at $\delta 158.0$ and doublet at $\delta 117.6$ could be assigned the double bond between C-14 and C-15 respectively indicated that the compound belongs to D-friedooleananes group (Nobuo et al., 1987).
From the fore going evidences it may be concluded that the triterpene core of the compound is Dfriedoolean- 14- en, 3 one or Taraxerone (Fig. 1).

\section{DISCUSSION}

The acetic acid induced writhing is normally used to evaluate the peripheral analgesic effect of drugs. The response is thought to be mediated by peritoneal mast cells, acid sensing ion channels and the prostaglandin pathway (Sutradhar et al., 2006). Therefore, it can be inferred that the inhibitory effect of the compound could be due to the inhibition of prostaglandin pathway.

The carrageenan-induced paw edema model in rats is known to be sensitive to cyclooxygenase inhibitors and has been used to evaluate the effect of non-steroidal anti-inflammatory agents, which primarily inhibit the cyclooxygenase involved in prostaglandin synthesis. In case of the time course of edema development in carrageenan induced paw edema model in rats is generally two phases are found. The first phase, which occurs between 0 to $2.5 \mathrm{~h}$ of injection of the phlogistic agent, has been attributed to the release of histamine or serotonin. The edema volume reaches to its maximum approximately $3 \mathrm{~h}$ post treatment and then begin to decline. The second phase of inflammatory reaction which is measured at $3 \mathrm{~h}$ is caused by the release of bradykinin, protease, prostaglandin and lysosome (Sutradhar et al., 2006). Therefore, it can be inferred that the inhibitory effect of the compound on the carrageenan induced inflammation could be due to the inhibition of enzyme cyclooxygenase leading to inhibition of prostaglandin synthesis.

Thus, the results of the present study demonstrates that the compound Taraxerone obtained from the petroleum ether extract of the fruits of Dregea volubilis consists of pentacyclic triterpenoid moiety and exhibited analgesic activity and anti-inflammatory activity which was found to be statistically significant at higher concentration in acute acetic acid induced writhing and in acute carrageenan induced rat paw 
edema model. However, a more extensive study is necessary to determine the exact mechanism(s) of action of the compound.

\section{ACKNOWLEDGEMENTS}

The authors are thankful to Dr. S. Bannerjee, Dr. N.B. Mandal and Mr. Rajendra Mahato, Steroid and Terpenoid Chemistry Division, Indian Institute of Chemical Biology, Jadavpur, Kolkata, West Bengal for cooperating in a step to isolate the pure compound from the extract of petroleum-ether.

\section{REFERENCES}

Bhatt KR, Mehata RK, Srivastava PN. (1977) A simple method for recording anti-inflammatory effect in rat paw oedema. Indian J. Physio. Pharm. 21, 399-400.

Goreti M, Masataka W, Shuntaro M, Kyoko I, Thies T. (2005) Areno annelated Estranes by Intermolecular Cycloaddition. 9th International Conference on Synthetic Organic Chemistry, Fukuoka, Japan, ECSOC-9, 309-311.

Majumder AM, Naik DG, Dandgee CN, Puntambekar HM. (2000) Anti- inflammatory Activity of Curcuma amada Roxb. in Albino Rats. Indian J. Pharmacol. 32, 375-377.

Mukherjee PK (2007) Quality Control of Herbal Drugs,
559, 2ND Edition, Business Horizons Pharmaceutical Publishers, New Delhi.

Mukherjee PK (2007) Quality Control of Herbal Drugs, pp.554-555, 2ND Edition, Business Horizons Pharmaceutical Publishers, New Delhi.

Nobuo S, Yoshi K, Takao I. (1987) Triterpenoids from Myrica Rubra. Phytochemistry 26, 217-219.

Panda N, Mandal NB, Banerjee S, Sahu NP, Koike K, Nikadio T, Weber M, Luger P. (2003) Polyhydroxy Pregnanes from Dregea volubilis. Phytochemistry 61, 8400-8403.

Parkes MW, Pickens JT. (1965) Conditions influencing the inhibition of analgesic drugs of the response to intra peritoneal injections of phenylbenzoquine in mice. Brit. J. Pharmacol. 25, 81-87.

Sutradhar RK, Rahman AM, Ahmad M, Bachar SC, Saha A, Guha SK. (2006) Bioactive alkaloid from Sida cordifolia Linn. with analgesic and anti-inflammatory activities. Iran. J. Pharmacol. T. 5, 175-178.

Sahu NP, Panda N, Mandal NB, Banejee S, Koike K, Nikadio T. (2002) Polyoxy Pregnane Glycosides from the Flowers of Dregea Volubilis. Phytochemistry 61, 383-388.

Shashi BM, Nandy AK, Roy G. (1992). Triterpenoids. Phytochemistry 31, 219.

Winter C A, Risely E A, Nuss G W (1957) Carrageenan induced oedema in hind paw of rat as assay for anti-inflammatory drugs. Exp. Biol. Med. 111, 544-547. 